\title{
Altered Mitochondrial DNA Methylation Pattern in Alzheimer Disease-Related Pathology and in Parkinson Disease
}

\author{
Marta Blanch, ${ }^{*}$ Jose Luis Mosquera, ${ }^{\dagger}$ Belén Ansoleaga, ${ }^{*}$ Isidre Ferrer, ${ }^{*}{ }^{\ddagger}$ and Marta Barrachina ${ }^{*}$
}

\begin{abstract}
From the Institute of Neuropathology, * Bellvitge University Hospital (Bellvitge Biomedical Research Institute) IDIBELL, L'Hospitalet de Llobregat; the Department of Statistics, ${ }^{\dagger}$ University of Barcelona, Barcelona; the Networked Biomedical Research Centre for NeuroDegenerative Disorders (CIBERNED), ${ }^{\ddagger}$ Madrid; and the Departament of Pathology and Experimental Therapeutics, ${ }^{\S}$ University of Barcelona, L'Hospitalet de Llobregat, Spain
\end{abstract}

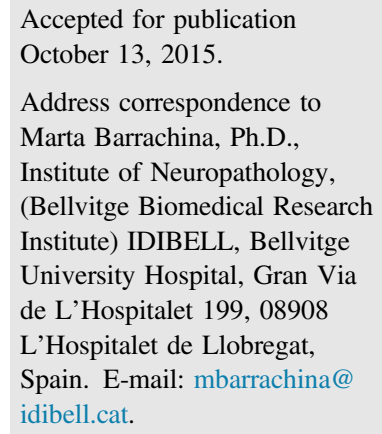

\begin{abstract}
Mitochondrial dysfunction is linked with the etiopathogenesis of Alzheimer disease and Parkinson disease. Mitochondria are intracellular organelles essential for cell viability and are characterized by the presence of the mitochondrial (mt)DNA. DNA methylation is a well-known epigenetic mechanism that regulates nuclear gene transcription. However, mtDNA methylation is not the subject of the same research attention. The present study shows the presence of mitochondrial 5-methylcytosine in $\mathrm{CpG}$ and non-CpG sites in the entorhinal cortex and substantia nigra of control human postmortem brains, using the 454 GS FLX Titanium pyrosequencer. Moreover, increased mitochondrial 5-methylcytosine levels are found in the D-loop region of mtDNA in the entorhinal cortex in brain samples with Alzheimer diseaserelated pathology (stages I to II and stages III to IV of Braak and Braak; $n=8$ ) with respect to control cases. Interestingly, this region shows a dynamic pattern in the content of mitochondrial 5methylcytosine in amyloid precursor protein/presenilin 1 mice along with Alzheimer disease pathology progression (3,6, and 12 months of age). Finally, a loss of mitochondrial 5-methylcytosine levels in the $D$-loop region is found in the substantia nigra in Parkinson disease $(n=10)$ with respect to control cases. In summary, the present findings suggest mtDNA epigenetic modulation in human brain is vulnerable to neurodegenerative disease states. (Am J Pathol 2016, 186: 385-397; http://dx.doi.org/ 10.1016/j.ajpath.2015.10.004)
\end{abstract}

Alzheimer disease (AD) and Parkinson disease (PD) are human neurodegenerative diseases characterized by intracellular aggregation of hyperphosphorylated tau that forms neurofibrillary tangles and extracellular accumulation of $\beta$-amyloid peptide in the form of extracellular senile plaques and by the occurrence of $\alpha$-synuclein-containing intraneuronal inclusions called Lewy bodies and aberrant neurites in AD and PD, respectively. ${ }^{1-4}$ Moreover, several studies have reported altered mitochondrial function in both diseases. ${ }^{3,5-9}$

Mitochondria are intracellular organelles that contain their own DNA, the mitochondrial DNA (mtDNA), which is a circular double-stranded DNA with a length of $16,569 \mathrm{bp}^{10}$ It codifies essential molecules for the biogenesis of this organelle: 22 tRNAs, 2 rRNAs, and 13 mitochondrial proteins of the respiratory chain [complex I: NADH dehydrogenase subunits $1,2,3,4,4 \mathrm{~L}, 5$, and 6 (ND1, ND2, ND3,
ND4, ND4L, ND5, and ND6); complex III: cytochrome b; complex IV: cytochrome oxidase I to III; and complex V: ATPase 6 and 8]. The rest of the mitochondrial proteins are codified in the nucleus. Moreover, mtDNA is devoid of intronic regions, and the only noncoding sequence is known as the control region or D-loop, which regulates mitochondrial transcription and replication. ${ }^{11}$ Interestingly, reduced

\footnotetext{
Supported by the Ministerio de Economia y Competitividad, Instituto de Salud Carlos III - Fondos FEDER, a way to build Europe grants PI10/ 01804 and PI14/00268 (M.Ba.), and Seventh Framework Program of the European Commission grant 278486: DEVELAGE (I.F.).

Disclosures: The data presented form part of a patent, with the application number PCT/ES2015/070230 (M.B1., I.F., and M.Ba.). The patent covers all of the data provided with the 454 GS FLX pyrosequencer.

Current address of J.L.M., Institute for Research in Biomedicine (IRB Barcelona), Barcelona, Spain.
} 
content and activity of complex I and IV subunits of the respiratory chain, such as ND4 in AD brains ${ }^{12-15}$ and ND6 in the substantia nigra in PD, have been reported. ${ }^{16-18}$ In addition, genetic studies have identified somatic mutations in several mitochondrially encoded cytochrome $\mathrm{c}$ oxidase genes and in the D-loop, probably altering mitochondrial transcription and replication, and mtDNA deletions in AD brains ${ }^{19-22}$ and in the substantia nigra in $\mathrm{PD} .^{23-25}$

The transcriptional control of mtDNA is exerted by nuclearencoded proteins such as mitochondrial transcription factor A, mitochondrial transcription factor $\mathrm{B} 1$, and mitochondrial transcription factor B2. ${ }^{26,27}$ In turn, polymorphisms in TFAM were also associated with a moderate risk factor for $\mathrm{AD}$ and $\mathrm{PD} .^{28-31}$ For the epigenetic control of the mitochondrial genome, there is an old debate about the existence or not of 5-methylcytosine $(5 \mathrm{mC})$ in this small circular genome. ${ }^{32-41}$ Recently, the first comprehensive map of $5 \mathrm{mC}$ in the mtDNA was published after analysis of 39 data sets available in the public domain. ${ }^{42}$ 5-Hydroxymethylcytosine $(5 \mathrm{hmC})$ was reported in cell lines and mouse brain in relation with the presence of the ten-eleventranslocation enzymes 1 to 3 family, which is involved in the conversion of $5 \mathrm{mC}$ into $5 \mathrm{hmC} .^{41,43}$ Moreover, the presence of $5 \mathrm{hmC}$ in the D-loop region in human and murine peripheral blood was shown by using methylated-DNA immunoprecipitation assays. ${ }^{32}$

There are no data about the existence of mitochondrial $5 \mathrm{mC}$ levels in the entorhinal cortex and substantia nigra in the human brain and practically nothing about neurodegenerative diseases. To our knowledge, only one study revealed high global mitochondrial $5 \mathrm{mC}$ levels with immunohistochemistry in the motor neurons of amyotrophic lateral sclerosis patients. ${ }^{44}$ For this reason, the present study was aimed at assessing the presence and extent of mtDNA $5 \mathrm{mC}$ levels in selected regions in the human brain, including $\mathrm{CpG}$ and non$\mathrm{CpG}$ sites, because methylation in nuclear non-CpG sites was reported to be present in human postmortem brains but absent in other human somatic cell types. ${ }^{45,46}$

To this end, the present study has analyzed the entorhinal cortex in control brains and in cases at the first stages of ADrelated pathology because this is the first cerebral region affected by neurofibrillary tangle pathology in $\mathrm{AD}$, and the substantia nigra in controls and PD cases because this is the paradigmatic region vulnerable to PD. In parallel, amyloid precursor protein/presenilin 1 (APP/PS1) mice, which are a model of familial AD, were also studied at 3, 6, and 12 months of age. Mitochondrial $5 \mathrm{mC}$ levels were measured with a deep sequencing technique with the 454 GS FLX Titanium pyrosequencer and mitochondrial $5 \mathrm{hmC}$ levels with hydroxymethylated DNA immunoprecipitation (hMeDIP) assay. This study provides the following new concepts to the mitoepigenetics field: i) existence of mitochondrial $5 \mathrm{mC}$ levels in $\mathrm{CpG}$ and non-CpG sites in human and mouse brains, ii) a differential mtDNA methylation profile in AD-related pathology and PD with their control samples, iii) a dynamic mtDNA methylation along disease progression in APP/PS1 mice, and iv) presence of mitochondrial $5 \mathrm{hmC}$ levels in human brain.

\section{Materials and Methods}

\section{Human Brain Samples}

Tissue samples were provided by the Neurological Tissue Bank, University of Barcelona - Hospital Clínic de Barcelona and the Institute of Neuropathology, HUB-ICOIDIBELL Brain Bank. The donation and procurement of samples were regulated by the ethics committee of both institutions. Half of each brain was maintained in $4 \%$ buffered formalin for structural and immunohistochemical study, whereas the other half was processed in coronal sections to be frozen at $-80^{\circ} \mathrm{C}$ and made available for biochemical study. The neuropathologic examination was performed in all control and diseased cases on 30 standardized sections of the cerebrum, cerebellum, and brainstem, which were stained with hematoxylin and eosin, and Klüver Barrera, or processed for immunohistochemistry to glial fibrillary acidic protein, microglial markers, $\beta$-amyloid, phosphorylated tau (antibody AT8), $\alpha$-synuclein, $\alpha \mathrm{B}$-crystalin, ubiquitin, and TDP-43. Cases with AD-related pathology and PD cases were staged according to current neuropathologic criteria. $^{47-50}$ Cases with mixed pathology (including vascular lesions) were excluded from the present study. Control brains were from individuals without neurologic manifestations and with no lesions in the neuropathologic study. All cases analyzed are summarized in Supplemental Table S1.

\section{Animals}

Male APP/PS1 transgenic mice and corresponding wild-type (C57BL/6J) mice were obtained from The Jackson Laboratory (Bar Harbor, ME). The APP/PS1 model expresses a chimeric mouse/human APP (Mo/HuAPP695swe: APP Swedish mutation) and a mutant human PS1 (PS1-dE9), both directed to central nervous system neurons. Mice were maintained under standard animal housing conditions in a 12-hour dark-light cycle with free access to food and water. Animal handling was conducted in accordance with ethical guidelines (European Communities Council Directive 86/609/EEC) and were approved by the local ethics committee.

\section{Total DNA Extraction}

Total DNA was isolated from the human entorhinal cortex and substantia nigra, and the mouse neocortex with the use of the DNeasy Blood and Tissue Kit (Qiagen, Madrid, Spain) according to the manufacturer's instructions.

\section{Bisulfite Treatment}

DNA (300 ng) was treated with bisulfite with the use of the EZ DNA Methylation Kit (Zymo Research, Ecogen, Barcelona, Spain) according to the supplier's instructions. The human and murine bisulfite-treated DNA was 
Table 1 Primer Sequences

\begin{tabular}{|c|c|c|}
\hline Primer name & Forward & Reverse \\
\hline Human D-loop & 5'-TAGGGGTTTTTTGATTATTATTTTT-3' & 5'-АСАААСАТТСААТТАТТАТТАТТАТАТССТ-3' \\
\hline Human MT-ND1 & 5'-АTGGTTAATTTTTTATTTTTTATTGTATTT-3' & 5'-ТААТТТАААТТТААТАСТСАСССТААТСАА- \\
\hline Human MT-ND6 & 5'-TTTAAGTTTTTTTTTATTTATGGGGG-3' & 5'-САААСААТАТТСААССААТААСТАСТАС- $3^{\prime}$ \\
\hline Murine D-loop & 5'-AGGATATATTTGTGTTATTTGATATATATT-3' & 5'-ААСТАТАТАСТАТССТTТСАТАССТTААС-3' \\
\hline
\end{tabular}

Specific primers for human regions amplified (D-loop: nt.16386-256; MT-ND1: nt.3313-3686; MT-ND6: nt.14190-14613, complementary reverse) which were based on the nucleotide position in NC_012920 GenBank sequence and murine D-loop (nt.15599-15979) based on GenBank DQ106412 number (http://www. ncbi.nlm.nih.gov/genbank).

ND, NADH dehydrogenase subunit.

resuspended in $30 \mu \mathrm{L}$ and $15 \mu \mathrm{L}$, respectively. All samples were bisulfite-treated in parallel, using the same bisulfite stock to avoid differences in bisulfite conversion rate among different commercial batches.

\section{FLX Primers Design for D-Loop, MT-ND1, and MT-ND6}

The primers for the FLX experiment were designed according to Roche's (Sant Cugat del Vallès, Spain) Technical Bulletin Genome Sequencer FLX System: Amplicon Fusion Primer Design Guidelines for GS FLX Titanium Series Lib-A Chemistry. The amplicon fusion primers designed contained a directional GS FLX Titanium Primer A or Primer B sequence (including a four-base library key sequence) at the $5^{\prime}$ portion of the oligonucleotide in addition to the templatespecific sequence at the $3^{\prime}$ end. Moreover, a multiplex identifier (MID) sequence was added between the Primer A (or Primer B) and the specific sequence for automated software identification of samples after pooling/multiplexing and sequencing. The primers used have the following components: forward primer (Primer A-Key-MID-template-specific sequence), 5'-CGTATCGCCTCCCTCGCGCCA-TCAGMID-template-specific sequence-3'; reverse primer (Primer B-Key-MID-template-specific sequence): 5'CTATGCGCCTTGCCAGCCCGC-TCAG-MID-templatespecific sequence- $3^{\prime}$. The primers used in this study were designed to avoid $\mathrm{CpG}$ sites. The template-specific sequences for each amplicon are indicated in Table 1. The specific sequence of MIDs for each patient and mouse is indicated in Tables 2 and 3, respectively.

\section{Amplicon Library Preparation}

The FLX PCRs for D-loop, MT-ND1, and MT-ND6 were performed according to the Amplicon Library Preparation Method Manual (GS FLX Titanium Series) of Roche. Total bisulfite-treated DNA (20 ng) per sample was used for FLX PCRs. Amplification of the bisulfite-converted DNA was performed in a reaction volume of $25 \mu \mathrm{L}$. Each PCR reaction mixture consisted of a final concentration of $1 \times$ FastStart $10 \times$ Buffer 2, $0.05 \mathrm{U} / \mu \mathrm{L}$ FastStart HiFi Polymerase (Roche), 200 $\mathrm{nmol} / \mathrm{L}$ each $\mathrm{dNTP}$, and $200 \mathrm{nmol} / \mathrm{L}$ each specific primer forward and reverse. The primers were synthesized with a high-performance liquid chromatography purification quality
(Sigma-Aldrich, Madrid, Spain). Amplifications were performed in a Verity Applied Biosystems Thermocycler (Applied Biosystems, Madrid, Spain) with the use of the following conditions: $94^{\circ} \mathrm{C}$ for 3 minutes and then 36 cycles at $94^{\circ} \mathrm{C}$ for 15 seconds, specific annealing temperature for each amplicon $\left(61^{\circ} \mathrm{C}\right.$ for MT- $N D 1,62^{\circ} \mathrm{C}$ for D-loop and MT-ND6, and $56^{\circ} \mathrm{C}$ for murine D-loop) for 45 seconds and $72^{\circ} \mathrm{C}$ for 1 minute, followed by a final extension step at $72^{\circ} \mathrm{C}$ for 8 minutes and a last hold at $4^{\circ} \mathrm{C}$. Two microliters of each PCR product was checked on $1.5 \%$ agarose gel stained with SybrSafe DNA Gel Stain (Invitrogen, Madrid, Spain).

\section{PCR Purification}

PCR product was purified with the Agencourt AMPure XP PCR Purification (Beckman Coulter, Madrid, Spain)

Table 2 MID Sequences for Each Patient Analyzed

\begin{tabular}{|c|c|}
\hline MID number & MID sequence \\
\hline 1 & $5^{\prime}-\mathrm{ACGAGTGCGT}-3^{\prime}$ \\
\hline 2 & $5^{\prime}-\mathrm{ACGCTCGACA}-3^{\prime}$ \\
\hline 3 & $5^{\prime}-\mathrm{AGACGCACTC}-3^{\prime}$ \\
\hline 4 & $5^{\prime}-\mathrm{AGCACTGTAG}-3^{\prime}$ \\
\hline 5 & $5^{\prime}-\mathrm{ATCAGACACG}-3^{\prime}$ \\
\hline 6 & $5^{\prime}-$ ATATCGCGAG- $3^{\prime}$ \\
\hline 7 & $5^{\prime}$-CGTGTCTCTA-3' \\
\hline 8 & $5^{\prime}$-CTCGCGTGTC-3' \\
\hline 9 & $5^{\prime}-$ TAGTATCAGC- $3^{\prime}$ \\
\hline 10 & $5^{\prime}-$ TСТСТАTGCG-3' \\
\hline 11 & $5^{\prime}-$ TGATACGTCT-3' \\
\hline 12 & $5^{\prime}-$ TACTGAGCTA-3' \\
\hline 13 & $5^{\prime}$-CATAGTAGTG-3' \\
\hline 14 & $5^{\prime}-\mathrm{CGAGAGATAC}-3^{\prime}$ \\
\hline 15 & $5^{\prime}-\mathrm{ATACGACGTA}-3^{\prime}$ \\
\hline 16 & $5^{\prime}-$ TCACGTACTA-3' \\
\hline 17 & $5^{\prime}-$ CGTCTAGTAC- $3^{\prime}$ \\
\hline 18 & $5^{\prime}-$ TCTACGTAGC- $3^{\prime}$ \\
\hline 19 & $5^{\prime}-$ TGTACTACTC- $3^{\prime}$ \\
\hline 20 & $5^{\prime}-\mathrm{ACGACTACAG}-3^{\prime}$ \\
\hline 21 & $5^{\prime}-$ CGTAGACTAG $-3^{\prime}$ \\
\hline 22 & $5^{\prime}-$ TACGAGTATG- $3^{\prime}$ \\
\hline 23 & $5^{\prime}$-TACTCTCGTG-3' \\
\hline 24 & $5^{\prime}-$ TAGAGACGAG $-3^{\prime}$ \\
\hline
\end{tabular}

Forward and reverse primers contain the MID sequence (a barcode for each case).

MID, multiplex identifier. 
Table 3 MID Sequences for Each Mouse Analyzed

\begin{tabular}{lll}
\hline Mouse phenotype & MID number & MID sequence \\
\hline WT, 3 months & 25 & $5^{\prime}$-TCGTCGCTCG-3' \\
APP/PS1, 3 months & 26 & $5^{\prime}$-ACATACGCGT-3' \\
APP/PS1, 3 months & 27 & $5^{\prime}$-ACGCGAGTAT-3' \\
APP/PS1, 3 months & 28 & $5^{\prime}$-ACTACTATGT-3' \\
WT, 3 months & 29 & $5^{\prime}$-ACTGTACAGT-3' \\
WT, 3 months & 30 & $5^{\prime}$-AGACTATACT-3' \\
WT, 3 months & 31 & $5^{\prime}$-AGCGTCGTCT-3' \\
APP/PS1, 3 months & 32 & $5^{\prime}$-AGTACGCTAT-3' \\
APP/PS1, 6 months & 33 & $5^{\prime}$-ATAGAGTACT-3' \\
APP/PS1, 6 months & 34 & $5^{\prime}$-CACGCTACGT-3' \\
APP/PS1, 6 months & 35 & $5^{\prime}$-CAGTAGACGT-3' \\
WT, 6 months & 36 & $5^{\prime}$-CGACGTGACT-3' \\
APP/PS1, 6 months & 37 & $5^{\prime}$-TACACACACT-3' \\
WT, 6 months & 38 & $5^{\prime}$-TACACGTGAT-3' \\
WT, 6 months & 39 & $5^{\prime}$-TACAGATCGT-3' \\
WT, 6 months & 40 & $5^{\prime}$-TACGCTGTCT-3' \\
WT, 12 months & 41 & $5^{\prime}$-TAGTGTAGAT-3' \\
WT, 12 months & 42 & $5^{\prime}$-TCGATCACGT-3' \\
APP/PS1, 12 months & 43 & $5^{\prime}$-TCGCACTAGT-3' \\
APP/PS1, 12 months & 44 & $5^{\prime}$-TCTAGCGACT-3' \\
APP/PS1, 12 months & 45 & $5^{\prime}$-TCTATACTAT-3' \\
WT, 12 months & 46 & $5^{\prime}$-TGACGTATGT-3' \\
APP/PS1, 12 months & 47 & $5^{\prime}$-TGTGAGTAGT-3' \\
APP/PS1, 12 months & 48 & $5^{\prime}$-ACAGTATATA-3' \\
\hline
\end{tabular}

Forward and reverse primers contain the MID sequence (a barcode for each case).

APP/PS1, amyloid precursor protein/presenilin 1; MID, multiplex identifier; WT, wild-type.

according to the instructions in Roche's Amplicon Library Preparation Method Manual (GS FLX Titanium Series).

\section{Library Quantitation and FLX Sequencing}

The quantitation and quality control of the libraries and the rest of the FLX sequencing protocol were performed by the Core Facilities-Genomic Platform of the Vall d'Hebron Institut de Recerca (Barcelona, Spain). The analysis of murine D-loop was performed by the Macrogen platform (Seoul, South Korea).

\section{Selection of Differentially Methylated Sites}

The sample size was determined statically before experimentation. Alignment and identification of $\mathrm{CpG}, \mathrm{CHG}$, and $\mathrm{CHH}$ sites and bisulfite conversion rates were performed with BiQ Analyzer HT software (Max Planck Institut für Informatik, Saabrücken, Germany). ${ }^{51}$ Quality control of raw data and all of the statistical analysis were performed with the free statistical language $\mathrm{R}$ (http://www.r-project.org, last accessed September 30, 2015) and bioconductor (http:// www.bioconductor.org, last accessed September 30, 2015).

The selection of differentially methylated sites was based on computing a Fisher's Exact Test statistic and calling differentially methylated those sites with an adjusted $P<0.05$ with the method of Benjamini and Hochberg. ${ }^{52}$

The $\beta$-value represented in Heatmaps is the ratio of methylated reads per site and the overall sum of methylated and unmethylated reads per site ${ }^{53}$; that is, $\beta_{i, j}=M /(M+U)$, where $M$ is the number of methylated reads in site (i) and MID $(j)$, and $U$ is the number of unmethylated reads in site $(i)$ and MID (j).

\section{hMeDIP Assay}

Chromatin shearing (between 200 and 500 bp) was obtained from human entorhinal cortex and substantia nigra genomic DNA, using the Bioruptor from Diagenode (Liege, Belgium). The resultant human DNA (500 ng) was immunoprecipitated with the hMeDIP kit (Diagenode) according to the manufacturer's instructions. As a negative control, immunoprecipitation was performed with rabbit serum provided with the kit. Moreover, the kit also provided three spikes or internal immunoprecipitation controls: an unmethylated DNA, a methylated DNA, and a hydroxymethylated DNA which were added to all samples analyzed. In parallel, an aliquot of chromatin sheared from each sample was separated as a loading control of the experiment (Input).

The analysis of MeDIPs was performed in $5 \mu \mathrm{L} \mathrm{SyBr}$ Green reaction (Promega, Madrid, Spain): $1 \mu \mathrm{L}$ hMeDIP or input was mixed with $0.4 \mu \mathrm{L}$ of both primers $(5 \mu \mathrm{mol} / \mathrm{L})$ and $2.5 \mu \mathrm{L}$ of master mix. Every experimental condition was performed in triplicate in 384-well optical plates with the use of the LightCycler 480 System (Roche). The reactions were performed with the following variables: $50^{\circ} \mathrm{C}$ for $2 \mathrm{mi}-$ nutes, $95^{\circ} \mathrm{C}$ for 10 minutes, and 40 cycles of $95^{\circ} \mathrm{C}$ for 15 seconds, and $60^{\circ} \mathrm{C}$ for 1 minute. PCR products were evaluated with SYBR green melting curve analyses. The primers used were the following: MT-NDI forward, 5'-GCAGTAGCCCAAACAATCTC-3'; MT-ND1 reverse, 5'-GTGTTCTTGTGTTGTGATAAGG-3'; MT-ND6 forward, 5'-CCAAAGACAACCATCATTCC-3'; MT-ND6 reverse, 5'-ATTGATTGTTAGCGGTGTGG-3'; D-loop forward, 5'-CCTCACCCACTAGGATACCAAC-3'; D-loop reverse, 5'-CACGGAGGATGGTGGTCAAG- $3^{\prime}$. The primers for the three spikes were included with the kit. The value of the percentage of input was calculated according to the instructions provided with the hMeDIP kit (Diagenode).

\section{RNA Purification}

The RNA from human entorhinal samples was purified with RNeasy Midi kit (Qiagen, Hilden, Germany) according to the protocol provided by the manufacturer. The concentration of each sample was obtained from $\mathrm{A}_{260}$ measurements with Nanodrop 1000. RNA integrity was tested using the Agilent 2100 BioAnalyzer (Agilent, Santa Clara, CA). 

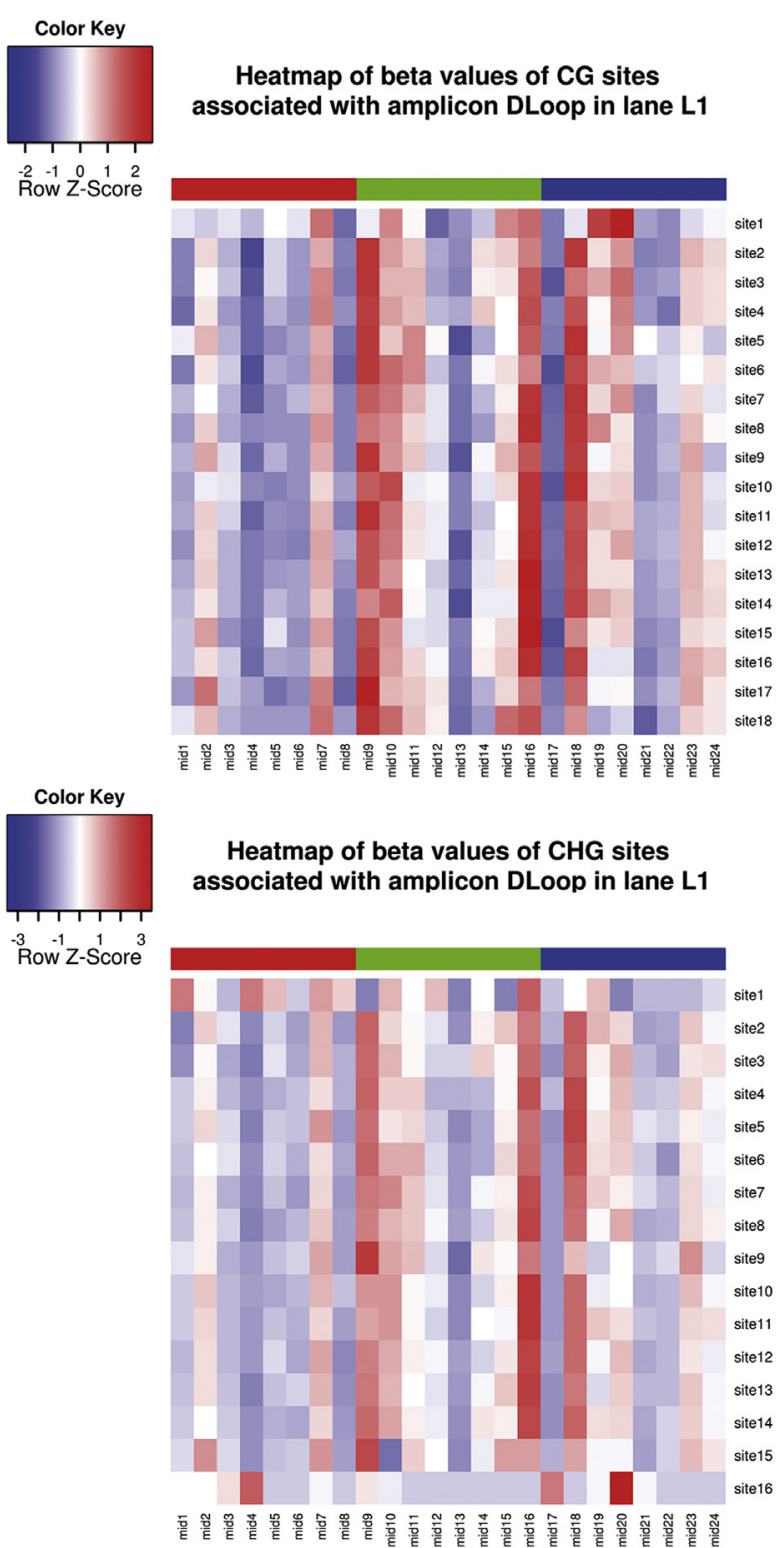

Color Key

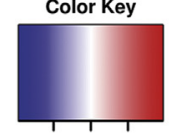

Row Z-S ${ }^{2}{ }^{2}$
Heatmap of beta values of $\mathrm{CHH}$ sites associated with amplicon DLoop in lane L1

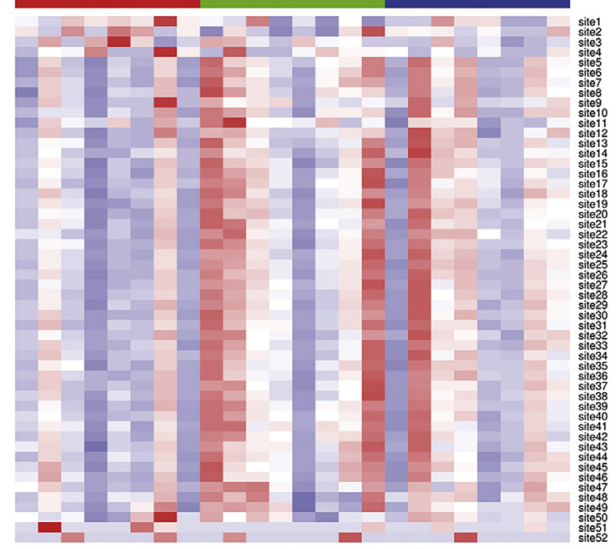

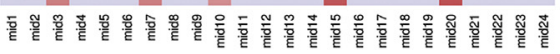

\section{Retrotranscription Reaction}

The retrotranscriptase reaction was performed with the High-Capacity cDNA Archive kit (Applied Biosystems, Madrid, Spain) according to the protocol provided by the supplier. Parallel reactions for each RNA sample were run in the absence of MultiScribe Reverse Transcriptase to assess the degree of contaminating genomic DNA.

\section{TaqMan PCR}

TaqMan PCR assays for every gene were performed in duplicate on cDNA samples in 384-well optical plates with the use of an ABI Prism 7900 Sequence Detection system (Applied Biosystems). For each $5 \mu \mathrm{L}$ TaqMan reaction, $2.5 \mu \mathrm{L}$ cDNA (dilution 1:100, which corresponds approximately to the cDNA from $12.5 \mathrm{ng}$ of RNA) was mixed with $0.25 \mu \mathrm{L} 20 \times$ TaqMan Gene Expression Assays and $2.25 \mu \mathrm{L}$ of $2 \times$ TaqMan Universal PCR Master Mix (Applied Biosystems). Parallel assays for each sample were performed with primers and probe for X-prolyl aminopeptidase 1 (XPNPEP1) for normalization. Standard curves were prepared for every gene analyzed with the use of serial dilutions of a control entorhinal case. Finally, all TaqMan PCR data were captured with the Sequence Detector Software version 1.9 (Applied Biosystems). The identification numbers for MT-NDI and XPNPEP1 TaqMan probes were Hs02596873_s1 and Hs00958026_m1, respectively.

\section{Statistical and mRNA/hMeDIP Data Analysis}

Data were analyzed with GraphPad Prism 5.0 software (GraphPad Software, San Diego, CA). The MT-ND1 mRNA expression levels and hMeDIP assays were evaluated with one-way analysis of variance (least significant difference post hoc test). Differences between mean values were considered statistically significant at $P<0.05$.

\section{Results}

The study was performed on 44 samples that included ADrelated pathology, PD, and control cases. Samples were processed in a single plate that consisted of two lanes. Samples of the entorhinal cortex of cases with AD-related

Figure 1 Heatmaps of $\beta$-values of $\mathrm{CpG}, \mathrm{CHG}$, and $\mathrm{CHH}$ sites associated with amplicon D-loop in the entorhinal cortex of AD-related pathology cases. Methylation heatmaps represent the extracted methylation patterns of the bisulfite reads graphically for all human cases analyzed (MIDs) in lane 1 (Table 2 and Supplemental Table S1). Columns are formed by the methylation sites found in the reference sequence that matches the analyzed methylation context, whereas rows correspond to the sequence reads. Horizontal lanes in the top of Heatmaps indicate the control group (red), AD I to II stages of Braak (green), and AD III to IV stages of Braak (blue) cases. A scale is shown, whereby positive (red) and negative (blue) values correspond, respectively, to higher and lower centered and scaled $\beta$-value (z-score) per site. AD, Alzheimer disease; MID, multiplex identifier. 

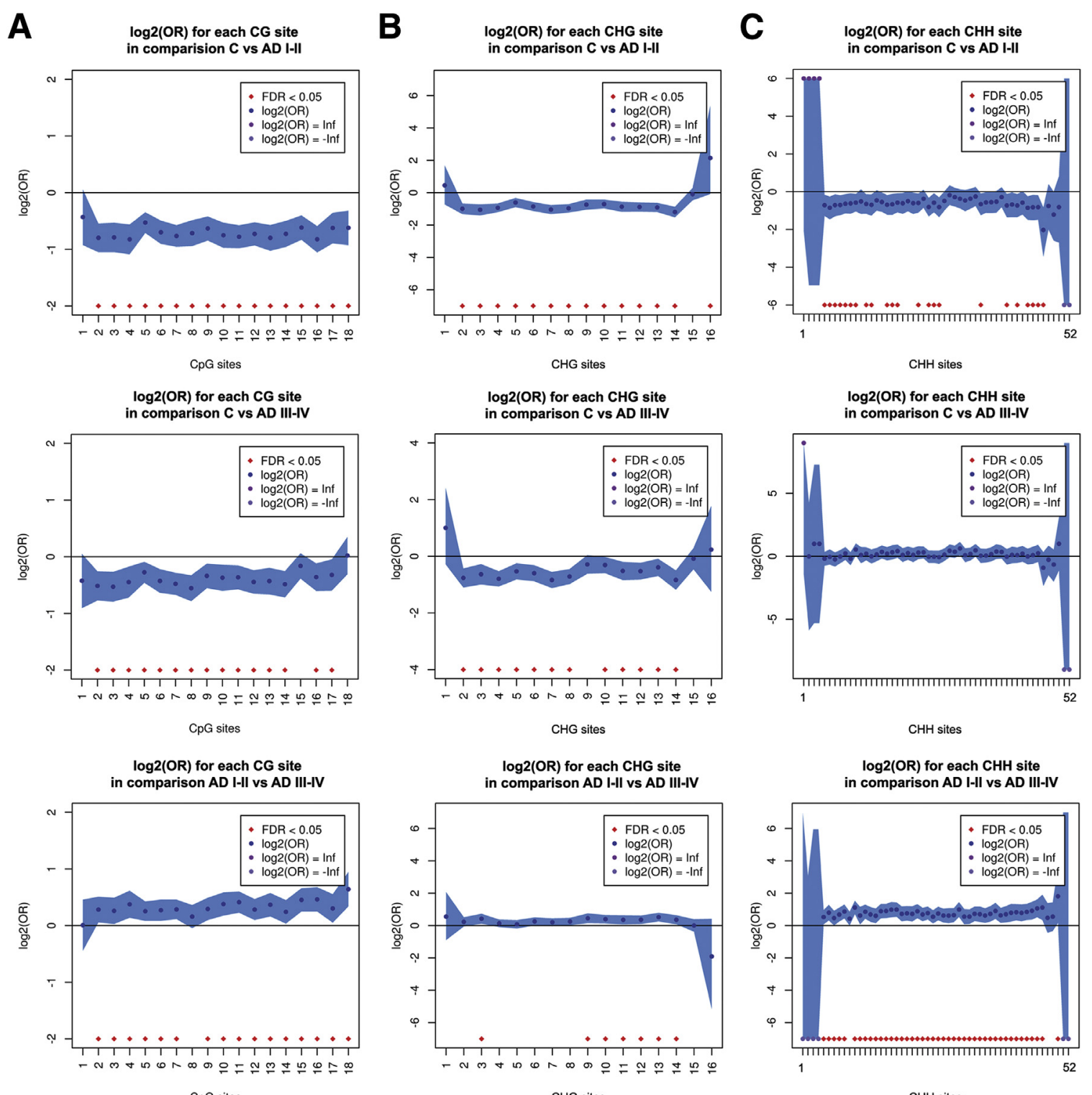

CHG sites
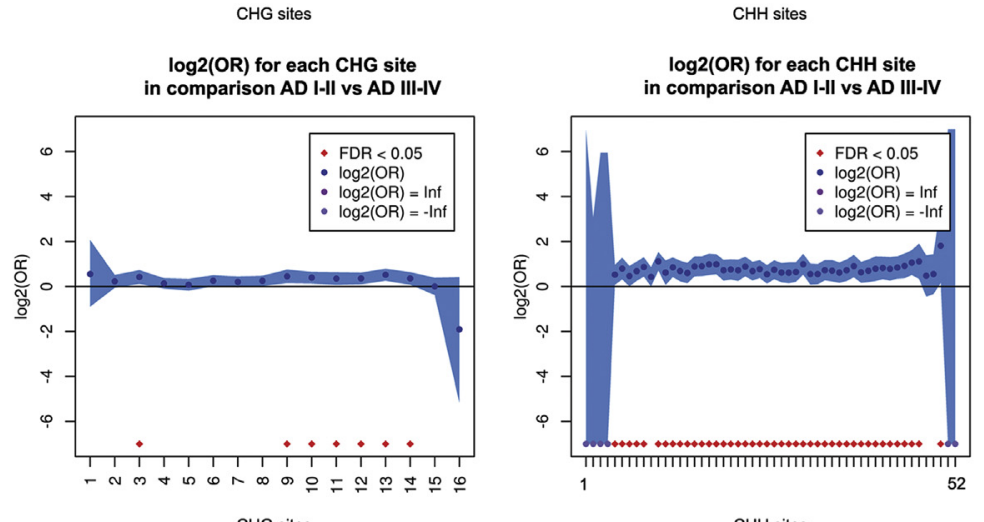

Figure 2 Log2(OR) plots for $\mathrm{CpG}(\mathbf{A}), \mathrm{CHG}(\mathbf{B})$, and CHH (C) sites in amplicon D-loop in the entorhinal cortex of AD-related pathology cases. On the $x$ axis are each site sorted from $5^{\prime}$ to $3^{\prime}$. Sites tagged with red diamonds are differentially methylated $(F D R<0.05)$. Blue dots are the $0 R$ estimate values, one per site, and cyan band is the union of all $95 \%$ CIs. AD, Alzheimer disease; C, control samples; FDR, false discovery rate.

pathology and corresponding control cases were analyzed for amplicons D-loop and MT-NDI and were allocated in lane 1 (Supplemental Table S1). Samples of the substantia nigra of PD cases and controls were analyzed for amplicons D-loop and MT-ND6 and were allocated in lane 2 (Supplemental Table S1). Each patient was identified with a MID sequence in the oligos used (Table 2 and Supplemental Table S1). The methylation of $\mathrm{CpG}$ sites and non-CpG sites (CHG and $\mathrm{CHH}$, where $\mathrm{H}=\mathrm{A}, \mathrm{T}$, or $\mathrm{C}$ ) was assessed with a 454 GS FLX Titanium pyrosequencer which generated 569,684 reads in the first lane and 513,579 in lane 2 . Alignments of reads for each MID, amplicon, and lane to the respective reference sequences were scored and their percentages of identity were close to $100 \%$ (Supplemental Figures S1 and S2). The bisulfite means \pm SD and median conversion rates for each locus and MID analyzed are shown in Supplemental Table S2.

The number of unmethylated reads was higher than the number of methylated reads per identified site, and few sites of methylation were missing (Supplemental Figures S3 and S4). Those reads that showed at least one missing site in the methylation pattern after alignment were removed from the analysis to avoid a bias at the time of quantification. This approach eluded the analysis of putative mitochondrial pseudogenes, whereas amplicons had $100 \%$ identity with mtDNA when entered into the National Center for Biotechnology Information Basic Local Alignment Search Tool (http://www.ncbi.nlm.nih. gov/blast). In addition, specificity for mtDNA target sequences of primers used was also checked on DNA 

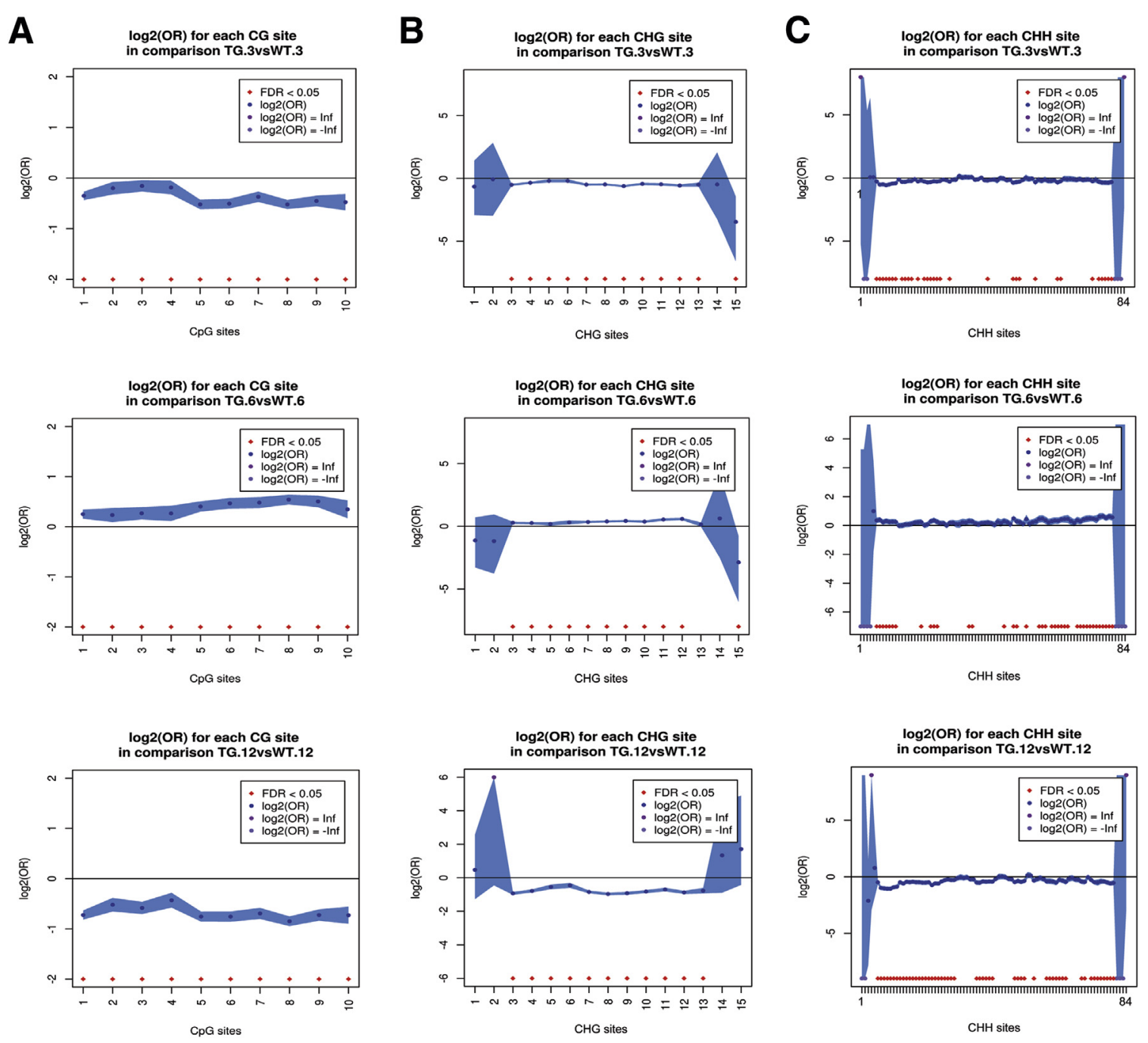

Figure 3 Log2(OR) plots for $\mathrm{CpG}(\mathbf{A}), \mathrm{CHG}(\mathbf{B})$, and CHH (C) sites in amplicon D-loop in the cerebral cortex of WT and APP/PS1 mice at different ages (3, 6, and 12 months old). On the $x$ axis are each site sorted from $5^{\prime}$ to $3^{\prime}$. Sites tagged with red diamonds are differentially methylated (FDR $\left.<0.05\right)$. Blue dots are the OR estimated values, one per site, and cyan band is the sum of all 95\% CIs. APP/PS1, amyloid precursor protein/presenilin 1; FDR, false discovery rate; TG, transgenic APP/PS1 mice; WT, wild-type mice.

extracted from osteosarcoma $143 \mathrm{~B} . \mathrm{TK}^{-} \mathrm{Rho}^{0}$ cells, which are devoid of mtDNA (Supplemental Figure S5). Most of the identified sites in $\mathrm{CpG}, \mathrm{CHG}$, and $\mathrm{CHH}$ sites were unmethylated (Supplemental Figure S3). However, differential methylated sites were also found (Supplemental Table S3).

\section{DNA Methylation Increases in D-Loop and Reduces in MT-ND1 Gene in Cases with Early-Stage AD-Related Pathology}

Increased DNA methylation of $\mathrm{CpG}$ and non-CpG sites (CHG and $\mathrm{CHH}$ ) in the D-loop region was observed in cases with AD-related pathology, stages I/II and III/IV of Braak (Figure 1). The degree of methylation was higher in cases with AD-related pathology for control samples and higher in stages I/II than in stages III/IV as represented in $\log 2(\mathrm{OR})$ plots (Figure 2). However, no differences were found in the methylation of $\mathrm{CHH}$ sites between controls and cases with AD-related pathology at stages III/IV. This is further represented in Pearl-Necklace diagrams, which summarize methylation information for the whole set of filtered reads in each CpG site (Supplemental Figure S6). The plots show that the increased methylation in $\mathrm{CpG}$ sites in AD-related pathology samples represents a small population of mtDNA.

MT-NDI analysis revealed that a few number of $\mathrm{CpG}$ and CHG sites were less methylated in cases with AD-related pathology at stages I/II and III/IV than in control samples, whereas no differences were found for $\mathrm{CHH}$ sites (Supplemental Figure S7). Next, we investigated whether these methylation changes showed an inverse relation with MT-ND1 mRNA levels. Only samples with an RNA integrity number greater than six were included in this analysis, which corresponds to a new set of human entorhinal cases (Supplemental Table S4). As Supplemental Figure S8 shows, an increase in MT-ND1 mRNA levels 


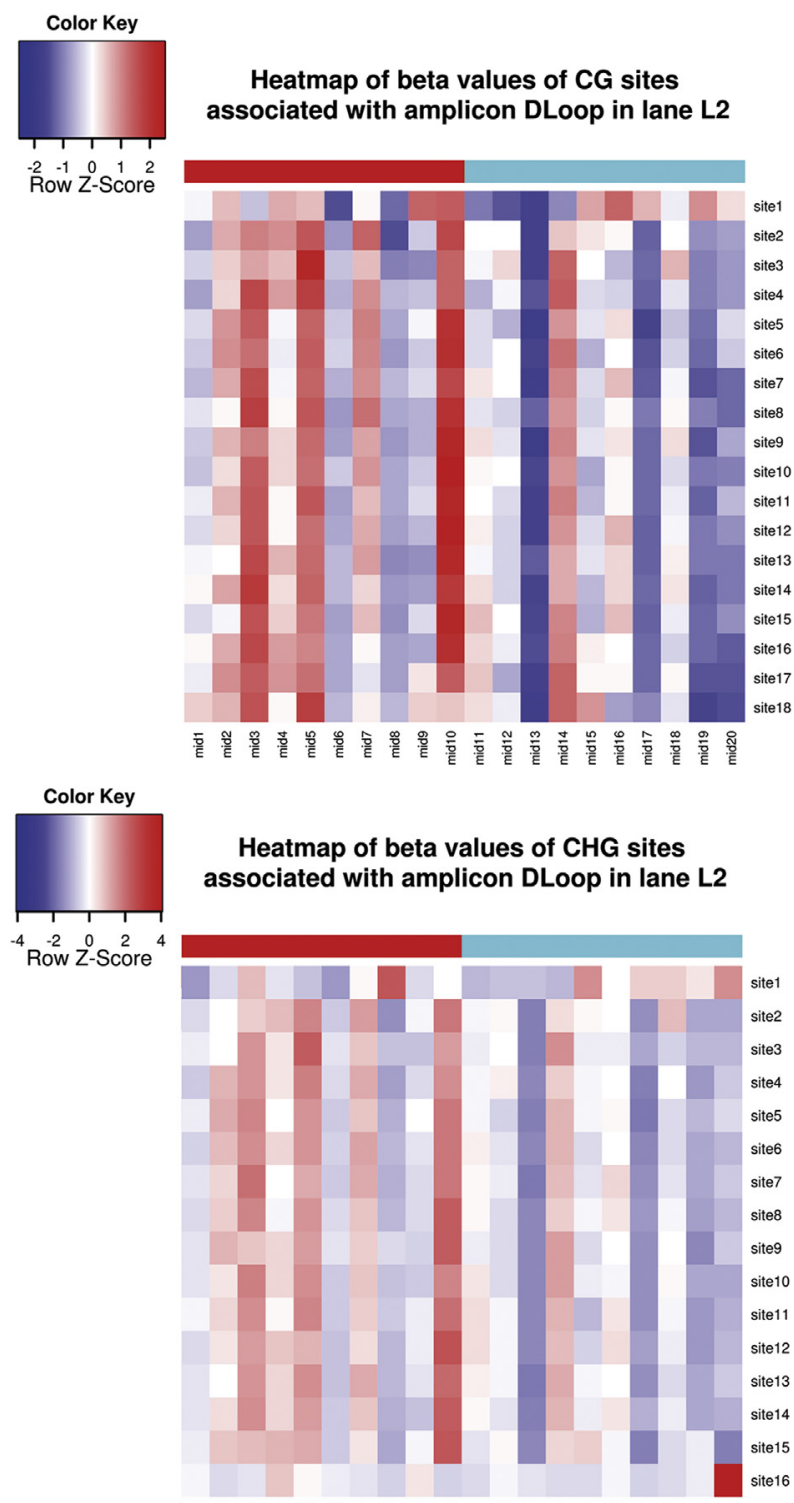

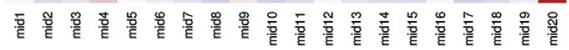

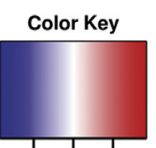
Row Z-Score
Heatmap of beta values of $\mathrm{CHH}$ sites associated with amplicon DLoop in lane L2

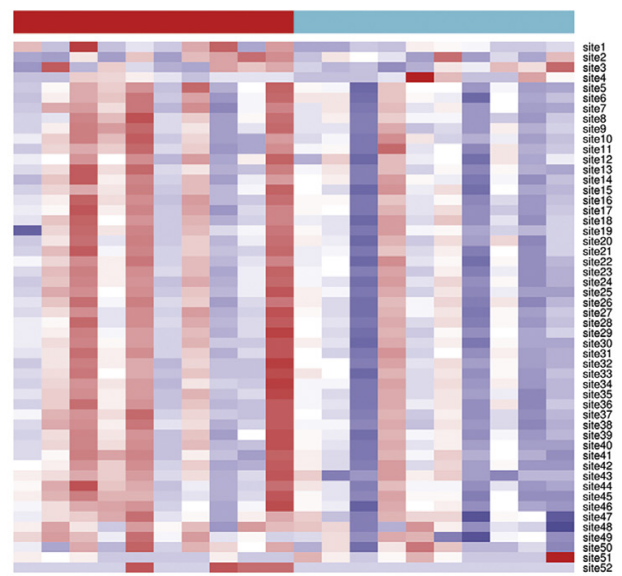

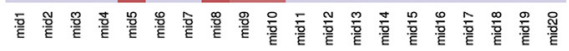

was found in AD-related pathology at stages V/VI for control cases and AD-related pathology at stages I/II.

Dynamic DNA Methylation Pattern in the D-Loop in the Cerebral Cortex of APP/PS1 Mice along AD Pathology Progression

On the basis of human results, we decided to check the $5 \mathrm{mC}$ levels in the murine D-loop, using an AD mouse model at different ages ( 3,6 , and 12 months). Therefore, a new run of pyrosequencing was performed. Each mouse was identified with an MID sequence in the oligos used (Table 3). The 454 GS FLX Titanium pyrosequencer generated 865,185 reads. The bisulfite means \pm SD and median conversion rates for each MID analyzed are shown in Supplemental Table S5. Differentially, $5 \mathrm{mC}$ levels were found between transgenic and wild-type mice along $\mathrm{AD}$ pathology progression in $\mathrm{CpG}$ sites (Figure 3A), CHG sites (Figure 3B), and to a lesser extent in $\mathrm{CHH}$ sites (Figure 3C). As shown in human brain, the $5 \mathrm{mC}$ levels represent a small population of total mtDNA (Supplemental Figure S9).

DNA Methylation Is Reduced in D-Loop and Maintained in MT-ND6 Gene in the Substantia Nigra in PD

In contrast to observations in the entorhinal cortex in $A D$, the D-loop region showed a loss of methylation in nearly all $\mathrm{CpG}$ and non-CpG sites in the substantia nigra in PD cases for control samples (Figures 4 and 5A). However, as in AD, the percentage of DNA methylation represented a small part of the total mtDNA (Supplemental Figure S10). No differences in methylation of $\mathrm{CpG}$ and non-CpG sites were found in MT-ND6 amplicon, except an increase in methylation in two $\mathrm{CHH}$ sites, in the substantia nigra in PD cases (Figure 5B).

Levels of Mitochondrial $5 \mathrm{hmC}$ Remain Unchanged in the D-Loop, MT-ND1, and MT-ND6

Finally, we also checked the levels of mitochondrial $5 \mathrm{hmC}$ with the use of the hMeDIP assay. To test the efficiency of the assay, we determined the $5 \mathrm{hmC}$ levels of an $\mathrm{hmC}$ spike added to an entorhinal cortex sample and to Rho ${ }^{0}$ cells. The anti-hmC antibody immunoprecipitated the hmC spike in both samples, whereas it did not recognize the other two

Figure 4 Heatmaps of $\beta$-values of $\mathrm{CpG}, \mathrm{CHG}$, and $\mathrm{CHH}$ sites associated with amplicon D-loop in substantia nigra of PD patients. Methylation heatmaps represent the extracted methylation patterns of the bisulfite reads graphically for all human cases analyzed in lane 2 (MIDs) (Table 2 and Supplemental Table S1). Columns are formed by the methylation sites found in the reference sequence matching the analyzed methylation context, whereas rows correspond to the sequence reads. Horizontal lanes in the top of Heatmaps indicate the control group (red) and PD patients (blue). A scale is shown, whereby positive (red) and negative (blue) values correspond, respectively, to higher and lower centered and scaled $\beta$-value (z-score) per site. MID, multiplex identifier; PD, Parkinson disease. 
A
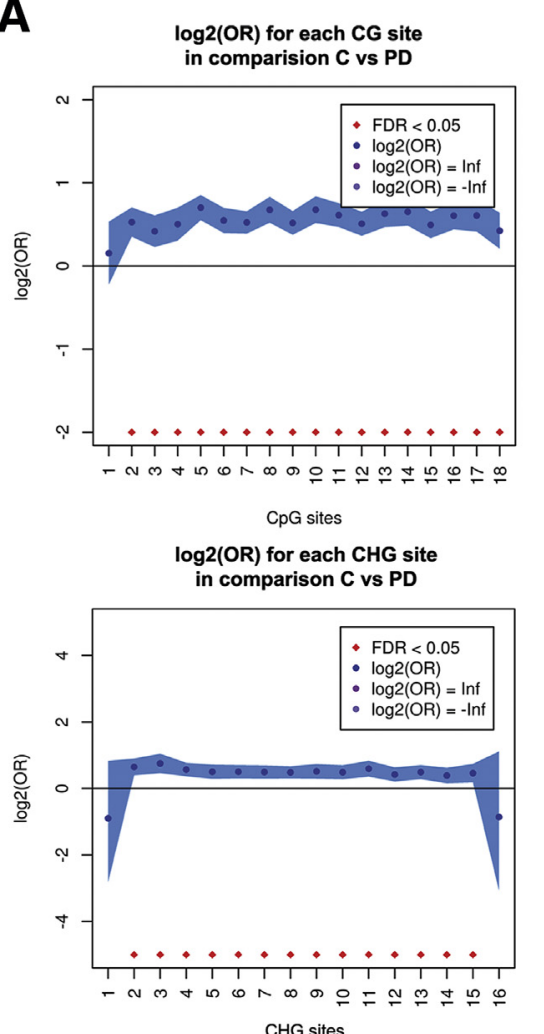

CHG sites

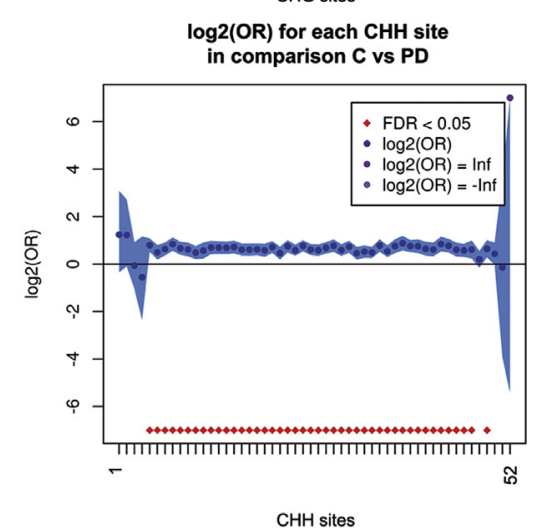

B
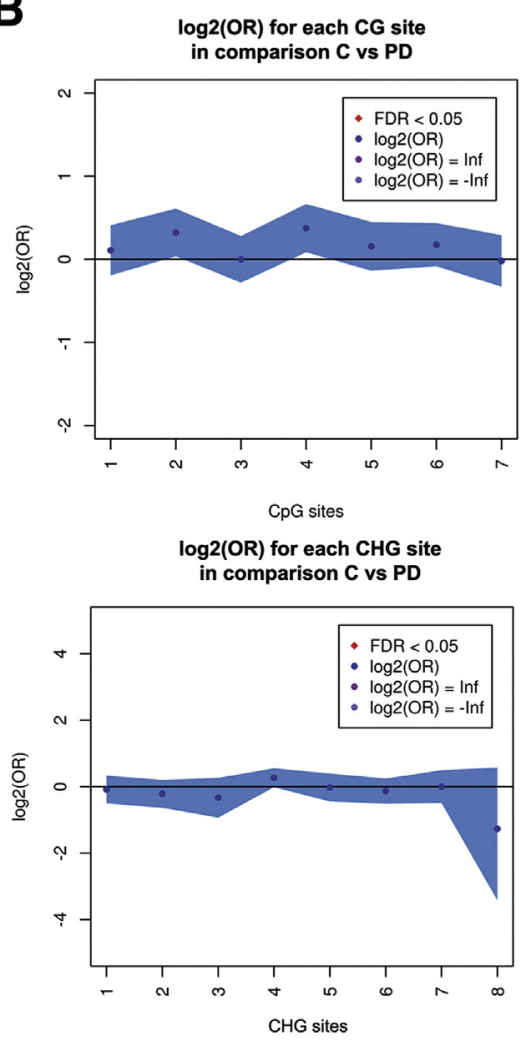

$\log 2(\mathrm{OR})$ for each CHH site

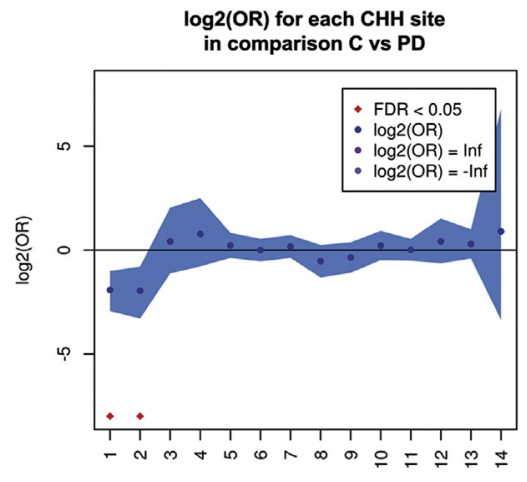

$\mathrm{CHH}$ sites
Figure 5 Log2(OR) plots for $\mathrm{CpG}$ and non-CpG ( $\mathrm{CHG}$ and $\mathrm{CHH}$ ) sites in the substantia nigra of PD patients. Amplicons D-loop (A) and MT-ND6 (B). On $x$ axis are each site sorted from $5^{\prime}$ to $3^{\prime}$. Sites tagged with red diamonds are differentially methylated (FDR $<0.05)$. Blue dots are the OR estimate values, one per site, and cyan band is the union of all $95 \%$ CIs. C, control samples; FDR, false discovery rate; MTND, mitochondrial NADH dehydrogenase subunit. PD, Parkinson disease. spikes also included in the tested samples (an unmethylated DNA and a methylated DNA) (Figure 6A). Moreover, the oligos used to determine the $5 \mathrm{hmC}$ levels in MT-ND1, MTND6, and D-loop did not amplify putative mitochondrial pseudogenes because no amplification was obtained in $\mathrm{Rho}^{0}$ cells. Therefore, the overall analysis performed in substantia nigra (Figure 6B) and entorhinal cortex (Figure 6C) samples revealed nonsignificant differences in $5 \mathrm{hmC}$ levels in the three loci studied.

\section{Discussion}

DNA methylation is a well-known epigenetic mechanism that regulates the expression of nuclear genes during development and in adulthood. ${ }^{54,55}$ Levels of $5 \mathrm{mC}$ are maintained in nuclear gene promoters and gene bodies through the activity of DNA methyltransferases. ${ }^{56}$ The existence of mitochondrial $5 \mathrm{mC}$ has been controversial for a long time. ${ }^{32-34,37,39-41}$ A study demonstrated for the first time human mtDNA methylation with the use of mass spectrometry analysis and mtDNA hypomethylation in Down syndrome. ${ }^{36}$ Yet it was also suggested that $\mathrm{CpG}$ methylation does not occur in human mtDNA. ${ }^{35}$ Importantly, the characterization of mitochondrial DNA methyltransferase $1^{41}$ has promoted growing interest in the study of epigenetic regulation of mtDNA. ${ }^{57,58}$

In the present study, a high number of reads $(>500,000)$ were used to analyze three mitochondrial loci, allowing the detection of a methylated mtDNA population in $\mathrm{CpG}$ and non-CpG sites at single base pair resolution. The overall study shows that methylated mtDNA represents only a small part of the total mtDNA. This aspect is in agreement with 

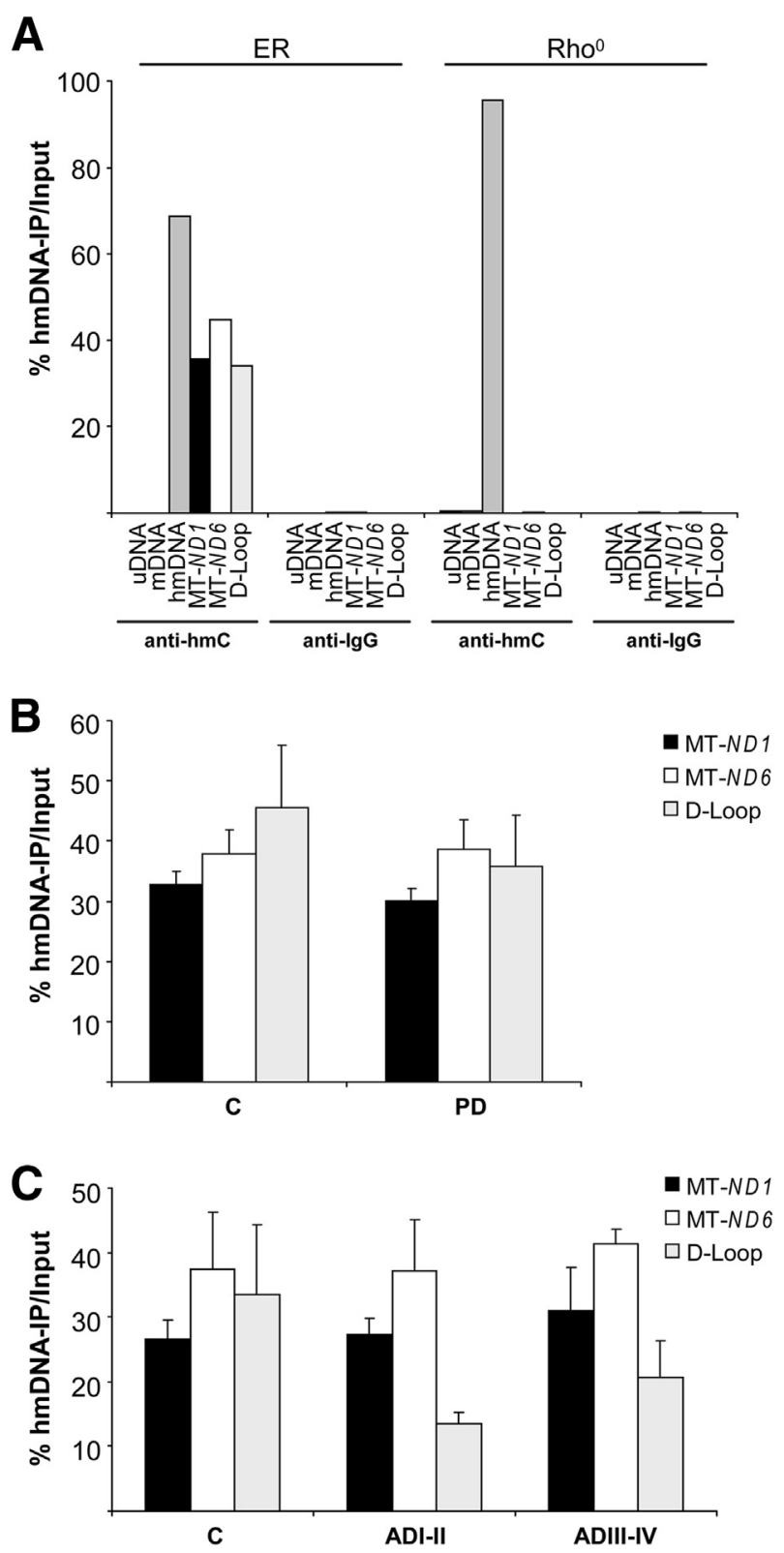

Figure 6 Levels of $\mathrm{hmC}$ were measured with hMeDIP assay in the MTND1, MT-ND6, and D-loop. A: Analysis of anti-hmC antibody efficiency and oligos specificity. ER corresponding to MID3, lane 1, Supplemental Table S1. B: Analysis of substantia nigra cases. C: Analysis of entorhinal cases. All human samples studied are indicated in Supplemental Table S1. Nonsignificant differences were found for all loci studied. Data are expressed as means \pm SEM. ER, entorhinal cortex sample; hmC, hydroxymethylcytosine; hMeDIP, hydroxymethylated DNA immunoprecipitation; IP, immunoprecipitated; mDNA, methylated DNA; MID, multiplex identifier; MT-ND, mitochondrial NADH dehydrogenase subunit; Rho ${ }^{\circ}$, osteosarcoma 143B.TK ${ }^{-}$Rho ${ }^{0}$ cells; uDNA, unmethylated DNA.

the predicted reduced percentage of methylation assigned to mtDNA. ${ }^{38-40}$ Note that the robustness of the present analysis showing the small but consistent methylation of mtDNA may explain the apparently controversial absence of $5 \mathrm{mC}$ reported in this small genome. ${ }^{34,35,37}$

This study shows increased $5 \mathrm{mC}$ levels in the D-loop region in the entorhinal cortex of cases with AD-related pathology stages I to II and III to IV of Braak and Braak with respect to control samples in most $\mathrm{CpG}$ and non-CpG sites. Interestingly, $5 \mathrm{mC}$ levels were higher in stages I/II than in stages III/IV. This altered mtDNA methylation profile was also replicated in the cerebral cortex of APP/PS1 mice, which present a memory decline and impaired learning at 6 months of age, whereas the first appearances of $\beta$-amyloid plaques and mitochondrial accumulation in aberrant neurites are at 3 months. ${ }^{59}$ The increase in 5mC levels found in 6-month-old APP/PS1 mice is quite relevant, because it shows a similar behavior to human $\mathrm{AD}$ brains.

Because MT-ND1 methylation by mitochondrial DNA methyltransferase 1 overexpression was observed in vitro, ${ }^{41}$ $5 \mathrm{mC}$ levels in MT-ND1 were also measured in AD-related pathology cases. Reduced $5 \mathrm{mC}$ levels in MT-ND1 were detected in the entorhinal cortex in cases of AD-related pathology. Although our aim was to identify altered mitochondrial $5 \mathrm{mC}$ levels at early $\mathrm{AD}$ stages of Braak and Braak, we performed the analysis of MT-ND1 mRNA levels in a new cohort of cases, including advanced AD stages (AD $\mathrm{V}$ to $\mathrm{VI}$ ). Our data suggest that changes in MT-NDI methylation levels in early $\mathrm{AD}$ stages could promote an increase in mRNA expression levels at stages V to VI of Braak and Braak. Of note is the discrepancy between the D-loop and MT-NDI methylation patterns, reminding us that in the dynamics of nuclear methylation $5 \mathrm{mC}$ gains in promoter genes are normally accompanied by $5 \mathrm{mC}$ losses in coding regions. ${ }^{53}$

Oxidative stress damage to ATP synthase accompanied by reduced enzymatic activity was reported in $\mathrm{AD}$ entorhinal cortex at stages I to II of Braak. ${ }^{60}$ Whether this change in the respiratory chain has any impact on the increase in $5 \mathrm{mC}$ levels in mtDNA is not known. The progression of AD stages is long, taking at least 16 years from stage I to stage II and about 14 years to pass from stage II to III. ${ }^{61}$ Therefore, considering such long periods of time, it is feasible that compensatory mechanisms may promote modifications in the methylation pattern in the D-loop region with disease progression and altered expression of MT-ND1 mRNA levels.

In contrast to D-loop data obtained in cases with $\mathrm{AD}$ related pathology, reduced $5 \mathrm{mC}$ levels were found in the substantia nigra in PD cases compared with the substantia nigra in control samples. This might be attributable to neuronal loss in this cerebral region. However, methylation levels in MT-ND6 were maintained in PD cases compared with controls, thus supporting the notion that reduced $5 \mathrm{mC}$ levels in the D-loop were not because of reduced neuronal content. Therefore, a differential mtDNA methylation profile is found between AD-related pathology and PD cases.

It should be taken into account that this study was performed in total homogenates from the enthorinal cortex and substantia nigra, which impairs the identification of the cellular types affected by changes in mtDNA methylation levels. However, note that in AD-related pathology stages I to II, the entorhinal cortex does not show gliosis, lending support to the idea that the increased mitochondrial $5 \mathrm{mC}$ levels occur in neuronal cells. 
We also checked the $5 \mathrm{hmC}$ levels in the three loci covered in this study. Interestingly, mitochondrial $5 \mathrm{hmC}$ levels were detected in both human cerebral regions analyzed with the hMeDIP assay, although nonsignificant differences were found in AD-related pathology and PD cases for control samples.

Several studies have reported mitochondrial impairment in $\mathrm{AD}$ and PD because of oxidative stress damage, mtDNA mutations/deletions, and mutations in mitochondrial genes codified in the nucleus. ${ }^{12-25,28-31}$ Our study provides new data for mitochondrial dysfunction, showing differential mtDNA methylation, mainly in the D-loop region, in the entorhinal cortex in cases with AD-related pathology and in the substantia nigra in PD. However, because mtDNA is transcribed as a polycistronic mRNA, ${ }^{62}$ further molecular and functional studies are required to elucidate the impact of mtDNA methylation in mitochondrial transcription both in normal conditions and in cases with AD-related pathology and PD. Moreover, another consideration is the consequence of mtDNA methylation in mtDNA replication. In this line, mtDNA replication is tightly linked to transcription, because mitochondrial DNA polymerase $\gamma$ requires an RNA primer. ${ }^{63}$ Indeed, the D-loop locus implicated in the processing of the RNA primer for mitochondrial replication was found to be methylated in human and murine peripheral blood, opening a door to the control of mitochondrial replication by mtDNA methylation. ${ }^{32,64}$

Finally, it remains to be determined whether a minimal threshold in the percentage of mtDNA methylation is enough to alter mitochondrial homeostasis or nuclear epigenetics. ${ }^{65-67}$ Another important aspect to be elucidated is the unraveling of whether modifications in the mtDNA methylation are primary events or rather a consequence of disease-dependent oxidative stress and mitochondrial dysfunction in AD and PD.

In summary, the present report shows the presence of mitochondrial $5 \mathrm{mC}$ levels in $\mathrm{CpG}$ and non-CpG sites in human brain at single base pair resolution and an altered mtDNA methylation pattern in AD and PD. Therefore, these data support the existence of epigenetic mtDNA regulation.

\section{Acknowledgments}

We thank Drs. Tomàs Pinós for $143 \mathrm{~B}^{\mathrm{T}} \mathrm{TK}^{-} \mathrm{Rho}^{0}$ cells, Ellen Gelpí for human samples, Olivia Casanueva for critical revision of the manuscript, Ester Aso for animal housing, and Tom Yohannan for editorial assistance.

\section{Supplemental Data}

Supplemental material for this article can be found at http://dx.doi.org/10.1016/j.ajpath.2015.10.004.

\section{References}

1. Dickson DW, Braak H, Duda JE, Duyckaerts C, Gasser T, Halliday GM, Hardy J, Leverenz JB, Del Tredici K, Wszolek ZK,
Litvan I: Neuropathological assessment of Parkinson's disease: refining the diagnostic criteria. Lancet Neurol 2009, 8:1150-1157

2. Duyckaerts C, Dickson DW: Neuropathology of Alzheimer's disease. Neurodegeneration: The Molecular Pathology of Dementia and Movement Disorders. Edited by Dickson DW. Basel, ISN Neuropath Press, 2003, pp 47-68

3. Ferrer I: Defining Alzheimer as a common age-related neurodegenerative process not inevitably leading to dementia. Prog Neurobiol 2012, 97:38-51

4. Jellinger K, Mizuno Y: Parkinson's disease. Neurodegeneration: The Molecular Pathology of Dementia and Movement Disorders. Edited by Dickson DW. Basel, ISN Neuropath Press, 2003, pp $159-187$

5. Coskun P, Wyrembak J, Schriner SE, Chen HW, Marciniack C, Laferla F, Wallace DC: A mitochondrial etiology of Alzheimer and Parkinson disease. Biochim Biophys Acta 2012, 1820:553-564

6. Ferrer I: Altered mitochondria, energy metabolism, voltagedependent anion channel, and lipid rafts converge to exhaust neurons in Alzheimer's disease. J Bioenerg Biomembr 2009, 41: $425-431$

7. Hattingen E, Magerkurth J, Pilatus U, Mozer A, Seifried C, Steinmetz H, Zanella F, Hilker R: Phosphorus and proton magnetic resonance spectroscopy demonstrates mitochondrial dysfunction in early and advanced Parkinson's disease. Brain 2009, 132:3285-3297

8. Keeney PM, Xie J, Capaldi RA, Bennett JP: Parkinson's disease brain mitochondrial complex I has oxidatively damaged subunits and is functionally impaired and misassembled. J Neurosci 2006, 26: $5256-5264$

9. Schapira AH: Mitochondrial dysfunction in neurodegenerative diseases. Neurochem Res 2008, 33:2502-2509

10. Anderson S, Bankier AT, Barrell BG, de Bruijn MH, Coulson AR, Drouin J, Eperon IC, Nierlich DP, Roe BA, Sanger F, Schreier PH, Smith AJ, Staden R, Young IG: Sequence and organization of the human mitochondrial genome. Nature 1981, 290:457-465

11. Asin-Cayuela J, Gustafsson CM: Mitochondrial transcription and its regulation in mammalian cells. Trends Biochem Sci 2007, 32: $111-117$

12. Aksenov MY, Tucker HM, Nair P, Aksenova MV, Butterfield DA, Estus S, Markesbery WR: The expression of several mitochondrial and nuclear genes encoding the subunits of electron transport chain enzyme complexes, cytochrome c oxidase, and NADH dehydrogenase, in different brain regions in Alzheimer's disease. Neurochem Res 1999, 24:767-774

13. Bosetti F, Brizzi F, Barogi S, Mancuso M, Siciliano G, Tendi EA, Murri L, Rapoport SI, Solaini G: Cytochrome c oxidase and mitochondrial F1F0-ATPase (ATP synthase) activities in platelets and brain from patients with Alzheimer's disease. Neurobiol Aging 2002, 23:371-376

14. Fukuyama R, Hatanpää K, Rapoport SI, Chandrasekaran K: Gene expression of ND4, a subunit of complex I of oxidative phosphorylation in mitochondria, is decreased in temporal cortex of brains of Alzheimer's disease patients. Brain Res 1996, 713:290-293

15. Kish SJ, Bergeron C, Rajput A, Dozic S, Mastrogiacomo F, Chang LJ, Wilson JM, DiStefano LM, Nobrega JN: Brain cytochrome oxidase in Alzheimer's disease. J Neurochem 1992, 59:776-779

16. Schapira AH, Cooper JM, Dexter D, Jenner P, Clark JB, Marsden CD: Mitochondrial complex I deficiency in Parkinson's disease. Lancet 1989, 1:1269

17. Schapira AH, Cooper JM, Dexter D, Clark JB, Jenner P, Marsden CD: Mitochondrial complex I deficiency in Parkinson's disease. J Neurochem 1990, 54:823-827

18. She H, Yang Q, Shepherd K, Smith Y, Miller G, Testa C, Mao Z: Direct regulation of complex I by mitochondrial MEF2D is disrupted in a mouse model of Parkinson disease and in human patients. J Clin Invest 2011, 121:930-940

19. Corral-Debrinski M, Horton T, Lott MT, Shoffner JM, McKee AC, Beal MF, Graham BH, Wallace DC: Marked changes in 
mitochondrial DNA deletion levels in Alzheimer brains. Genomics 1994, 23:471-476

20. Coskun PE, Beal MF, Wallace DC: Alzheimer's brains harbor somatic mtDNA control-region mutations that suppress mitochondrial transcription and replication. Proc Natl Acad Sci U S A 2004, 101: 10726-10731

21. Coskun PE, Wyrembak J, Derbereva O, Melkonian G, Doran E, Lott IT, Head E, Cotman CW, Wallace DC: Systemic mitochondrial dysfunction and the etiology of Alzheimer's disease and Down syndrome dementia. J Alzheimers Dis 2010, 20:S293-S310

22. Hamblet NS, Ragland B, Ali M, Conyers B, Castora FJ: Mutations in mitochondrial-encoded cytochrome c oxidase subunits I, II, and III genes detected in Alzheimer's disease using single-strand conformation polymorphism. Electrophoresis 2006, 27:398-408

23. Bender A, Krishnan KJ, Morris CM, Taylor GA, Reeve AK, Perry RH, Jaros E, Hersheson JS, Betts J, Klopstock T, Taylor RW, Turnbull DM: High levels of mitochondrial DNA deletions in substantia nigra neurons in aging and Parkinson disease. Nat Genet 2006, 38:515-517

24. Lin MT, Cantuti-Castelvetri I, Zheng K, Jackson KE, Tan YB, Arzberger T, Lees AJ, Betensky RA, Beal MF, Simon DK: Somatic mitochondrial DNA mutations in early Parkinson and incidental Lewy body disease. Ann Neurol 2012, 71:850-854

25. Müller SK, Bender A, Laub C, Högen T, Schlaudraff F, Liss B, Klopstock T, Elstner M: Lewy body pathology is associated with mitochondrial DNA damage in Parkinson's disease. Neurobiol Aging 2013, 34:2231-2233

26. Falkenberg M, Gaspari M, Rantanen A, Trifunovic A, Larsson NG, Gustafsson CM: Mitochondrial transcription factors B1 and B2 activate transcription of human mtDNA. Nat Genet 2002, 31: 289-294

27. Shi Y, Dierckx A, Wanrooij PH, Wanrooij S, Larsson NG, Wilhelmsson LM, Falkenberg M, Gustafsson CM: Mammalian transcription factor $\mathrm{A}$ is a core component of the mitochondrial transcription machinery. Proc Natl Acad Sci U S A 2012, 109: $16510-16515$

28. Alvarez V, Corao AI, Sánchez-Ferrero E, De Mena L, AlonsoMontes C, Huerta C, Blázquez M, Ribacoba R, Guisasola LM, Salvador C, García-Castro M, Coto E: Mitochondrial transcription factor A (TFAM) gene variation in Parkinson's disease. Neurosci Lett 2008, 432:79-82

29. Belin AC, Björk BF, Westerlund M, Galter D, Sydow O, Lind C, Pernold K, Rosvall L, Håkansson A, Winblad B, Nissbrandt H, Graff C, Olson L: Association study of two genetic variants in mitochondrial transcription factor A (TFAM) in Alzheimer's and Parkinson's disease. Neurosci Lett 2007, 420:257-262

30. Gaweda-Walerych K, Safranow K, Maruszak A, Bialecka M, Klodowska-Duda G, Czyzewski K, Slawek J, Rudzinska M, Styczynska M, Opala G, Drozdzik M, Kurzawski M, Szczudlik A, Canter JA, Barcikowska M, Zekanowski C: Mitochondrial transcription factor A variants and the risk of Parkinson's disease. Neurosci Lett 2010, 469:24-29

31. Günther C, von Hadeln K, Müller-Thomsen T, Alberici A, Binetti G, Hock C, Nitsch RM, Stoppe G, Reiss J, Gal A, Finckh U: Possible association of mitochondrial transcription factor A (TFAM) genotype with sporadic Alzheimer disease. Neurosci Lett 2004, 369:219-223

32. Bellizzi D, D’Aquila P, Scafone T, Giordano M, Riso V, Riccio A, Passarino G: The control region of mitochondrial DNA shows an unusual CpG and non-CpG methylation pattern. DNA Res 2013, 20 $537-547$

33. Dawid IB: 5-methylcytidylic acid: absence from mitochondrial DNA of frogs and HeLa cells. Science 1974, 184:80-81

34. Groot GS, Kroon AM: Mitochondrial DNA from various organisms does not contain internally methylated cytosine in -CCGG- sequences. Biochim Biophys Acta 1979, 564:355-357

35. Hong EE, Okitsu CY, Smith AD, Hsieh CL: Regionally specific and genome-wide analyses conclusively demonstrate the absence of $\mathrm{CpG}$ methylation in human mitochondrial DNA. Mol Cell Biol 2013, 33: 2683-2690

36. Infantino V, Castegna A, Iacobazzi F, Spera I, Scala I, Andria G, Iacobazzi V: Impairment of methyl cycle affects mitochondrial methyl availability and glutathione level in Down's syndrome. Mol Genet Metab 2011, 102:378-382

37. Maekawa M, Taniguchi T, Higashi H, Sugimura H, Sugano K, Kanno T: Methylation of mitochondrial DNA is not a useful marker for cancer detection. Clin Chem 2004, 50:1480-1481

38. Nass MM: Differential methylation of mitochondrial and nuclear DNA in cultured mouse, hamster and virus-transformed hamster cells. In vivo and in vitro methylation. J Mol Biol 1973, 80:155-175

39. Pollack Y, Kasir J, Shemer R, Metzger S, Szyf M: Methylation pattern of mouse mitochondrial DNA. Nucleic Acids Res 1984, 12: 4811-4824

40. Shmookler Reis RJ, Goldstein S: Mitochondrial DNA in mortal and immortal human cells. Genome number, integrity, and methylation. J Biol Chem 1983, 258:9078-9085

41. Shock LS, Thakkar PV, Peterson EJ, Moran RG, Taylor SM: DNA methyltransferase 1, cytosine methylation, and cytosine hydroxymethylation in mammalian mitochondria. Proc Natl Acad Sci U S A 2011, 108:3630-3635

42. Ghosh S, Sengupta S, Scaria V: Comparative analysis of human mitochondrial methylomes shows distinct patterns of epigenetic regulation in mitochondria. Mitochondrion 2014, 18:58-62

43. Dzitoyeva S, Chen H, Manev H: Effect of aging on 5-hydroxymethylcytosine in brain mitochondria. Neurobiol Aging 2012, 33: 2881-2891

44. Chestnut BA, Chang Q, Price A, Lesuisse C, Wong M, Martin LJ: Epigenetic regulation of motor neuron cell death through DNA methylation. J Neurosci 2011, 31:16619-16636

45. Varley KE, Gertz J, Bowling KM, Parker SL, Reddy TE, PauliBehn F, Cross MK, Williams BA, Stamatoyannopoulos JA, Crawford GE, Absher DM, Wold BJ, Myers RM: Dynamic DNA methylation across diverse human cell lines and tissues. Genome Res 2013, 23:555-567

46. Ziller MJ, Müller F, Liao J, Zhang Y, Gu H, Bock C, Boyle P, Epstein CB, Bernstein BE, Lengauer T, Gnirke A, Meissner A: Genomic distribution and inter-sample variation of non-CpG methylation across human cell types. PLoS Genet 2011, 7:e1002389

47. Braak H, Braak E: Neuropathological staging of Alzheimer-related changes. Acta Neuropathol 1991, 82:239-259

48. Braak H, Braak E: Temporal sequence of Alzheimer's disease-related pathology. Edited by Peters A, Morrison JH. Cerebral Cortex. New York, Kluwer Academic/Plenum Publishers, 1999, pp 475-512

49. Braak H, Alafuzoff I, Arzberger T, Kretzschmar H, Del Tredici K: Staging of Alzheimer disease-associated neurofibrillary pathology using paraffin sections and immunocytochemistry. Acta Neuropathol 2006, 112:389-404

50. Braak H, Del Tredici K, Rüb U, de Vos RA, Jansen Steur EN, Braak E: Staging of brain pathology related to sporadic Parkinson's disease. Neurobiol Aging 2003, 24:197-211

51. Lutsik P, Feuerbach L, Arand J, Lengauer T, Walter J, Bock C: BiQ Analyzer HT: locus-specific analysis of DNA methylation by highthroughput bisulfite sequencing. Nucleic Acids Res 2011, 39: W551-W556

52. Benjamini Y, Hochberg Y: Controlling the false discovery rate: a practical and powerful approach to multiple testing. J R Stat Soc Ser B Stat Methodol 1995, 57:289-300

53. Du P, Zhang X, Huang CC, Jafari N, Kibbe WA, Hou L, Lin SM: Comparison of Beta-value and M-value methods for quantifying methylation levels by microarray analysis. BMC Bioinformatics 2010, 11:587

54. Jones PA: Functions of DNA methylation: islands, start sites, gene bodies and beyond. Nat Rev Genet 2012, 13:484-492

55. Suzuki MM, Bird A: DNA methylation landscapes: provocative insights from epigenomics. Nat Rev Genet 2008, 9:465-476 
56. Feng J, Zhou Y, Campbell SL, Le T, Li E, Sweatt JD, Silva AJ, Fan G: Dnmt1 and Dnmt3a maintain DNA methylation and regulate synaptic function in adult forebrain neurons. Nat Neurosci 2010, 13: 423-430

57. Chinnery PF, Elliott HR, Hudson G, Samuels DC, Relton CL: Epigenetics, epidemiology and mitochondrial DNA diseases. Int J Epidemiol 2012, 41:177-187

58. Manev H, Dzitoyeva S, Chen H: Mitochondrial DNA: a blind spot in neuroepigenetics. Biomol Concepts 2012, 3:107-115

59. Aso E, Lomoio S, López-González I, Joda L, Carmona M, FernándezYagüe N, Moreno J, Juvés S, Pujol A, Pamplona R, Portero-Otin M, Martín V, Díaz M, Ferrer I: Amyloid generation and dysfunctional immunoproteasome activation with disease progression in animal model of familial Alzheimer's disease. Brain Pathol 2012, 22:636-653

60. Terni B, Boada J, Portero-Otin M, Pamplona R, Ferrer I: Mitochondrial ATP-synthase in the entorhinal cortex is a target of oxidative stress at stages I/II of Alzheimer's disease pathology. Brain Pathol 2010, 20:222-333

61. Ohm TG, Müller H, Braak H, Bohl J: Close-meshed prevalence rates of different stages as a tool to uncover the rate of Alzheimer's disease-related neurofibrillary changes. Neuroscience 1995, 64: 209-217

62. Mercer TR, Neph S, Dinger ME, Crawford J, Smith MA, Shearwood AM, Haugen E, Bracken CP, Rackham O, Stamatoyannopoulos JA, Filipovska A, Mattick JS: The human mitochondrial transcriptome. Cell 2011, 146:645-658

63. Kasiviswanathan R, Collins TR, Copeland WC: The interface of transcription and DNA replication in the mitochondria. Biochim Biophys Acta 2012, 1819:970-978

64. Ferreira A, Serafim TL, Sardão VA, Cunha-Oliveira T: Role of mtDNA-related mitoepigenetic phenomena in cancer. Eur J Clin Invest 2015, 45:44-49

65. Devall M, Mill J, Lunnon K: The mitochondrial epigenome: a role in Alzheimer's disease? Epigenomics 2014, 6:665-675

66. Smiraglia DJ, Kulawiec M, Bistulfi GL, Gupta SG, Singh KK: A novel role for mitochondria in regulating epigenetic modification in the nucleus. Cancer Biol Ther 2008, 7:1182-1190

67. D'Aquila P, Bellizzi D, Passarino G: Mitochondria in health, aging and diseases: the epigenetic perspective. Biogerontology 2015, 16 : $569-585$ 